\title{
PENERAPAN BALANCE SCORECARD SEBAGAI TOLAK UKUR PENGUKURAN KINERJA PADA HOTEL ELRESAS LAMONGAN
}

\author{
*) Mohamad Rizal Nur Irawan \\ Prodi Manajemen, Fakultas Ekonomi, Universitas Islam Lamongan \\ Jl. Veteran No. 53A Lamongan \\ Telp. (0322) 324706, Faks. (0322) 324706 \\ rizalirawan@unisla.ac.id / rijalunisla@gmail.com
}

\begin{abstract}
ABSTRAK
Untuk memasuki lingkungan bisnis yang kompetitif diciptakan suatu metode pendekatan Balance Scorecard. Rumusan Masalah untuk mengetahui penerapan Balance Scorecard sebagai tolak ukur pengukuran kinerja pada Hotel Elresas Lamongan dan variabel apa yang berpengaruh paling dominan terhadap kinerja. Populasi dalam penelitian ini adalah pimpinan, karyawan, pelanggan dan data pada Hotel Elresas Lamongan. Sampel sebanyak 100 responden, teknik pengumpulan data dengan wawancara, observasi, dokumentasi, studi kepustakaan dan kuisioner. Metode analisis data dalam penelitian ini menggunakan Uji Validitas dan Uji Reliabilitas, Regresi Linier Berganda, Uji t dan Uji F. Hasil perhitungan Balance Scorecard yang meliputi perspektif pertumbuhan dan perkembangan, perspektif proses bisnis internal, perspektif pelanggan, dan perspektif keuangan menunjukan bahwa hasil penelitian di Hotel Elresas Lamongan adalah baik. Hasil persamaan Regresi Linier Berganda $\mathrm{Y}=8,025$ $0,244\left(\mathrm{X}_{1}\right)+0,530\left(\mathrm{X}_{2}\right)+0,258\left(\mathrm{X}_{3}\right)+0,282\left(\mathrm{X}_{4}\right)$. Variabel yang paling dominan adalah variabel Perspektif Proses Bisnis Internal dengan $t_{\text {hitung }}$ tertinggi 9,588.
\end{abstract}

Kata kunci : balance scorecard, kinerja.

\section{PENDAHULUAN}

Menetapkan metode Balance Scorecard para manajer perusahaan akan mampu mengukur bagaimana unit bisnis mereka melakukan penciptaan nilai saat ini dengan tetap mempertimbangkan kepentingankepentingan masa yang akan datang. Balance Scorecard merupakan suatu sistem manajemen, pengukuran, dan pengendalian yang secara cepat, tepat, dan komperhensif dapat memberikan pemahaman kepada manajer tentang performa bisnis.

Memasuki era globalisasi perdagangan antar negara, pimpinan hotel di Indonesia perlu memfokuskan strategi perencanaan, pengorganisasian, pengoperasian dan pengendalian sehingga siap dengan daya saing di tingkat global, di era tersebut konsumen dapat bebas 
memilih hotel mana yang mampu memberikan pelayanan memuaskan, profesional dengan harga bersaing sehingga strategi dan kinerja hotel pun harus berorientasi pada keinginan pelanggan tersebut. Untuk itu diterapkan Balance Scorecard yang diharapkan menjawab tuntutan dan tantangan zaman.

Hotel Elresas Lamongan merupakan salah satu Hotel di Lamongan yang berusaha memberikan pelayanan penginapan secara profesionalisme dan meningkatkan mutu terus menerus. Memaksa pihak Hotel Elresas Lamongan untuk selalu memperbaiki kinerjanya, agar dapat menambah kepercayaan pengunjung atas pelayanan Hotel Elresas Lamongan. Kepercayaan ini sangatlah penting, mengingat pengunjung merupakan pengguna jasanya.

Melihat fenomena tersebut di atas, maka perlu digunakan alternatif pengukuran kinerja Hotel Elresas Lamongan dengan menggunakan Balance Scorecard yang lebih komprehensif, akurat, terukur karena dalam menilai kinerja suatu organisasi tidak hanya dinilai dari aspek keuangan saja, tetapi juga dinilai dari aspek non keuangan.

\section{LANDASAN TEORI}

\section{Sistem Pengukuran Kinerja}

Kinerja dapat diartikan sebagai salah satu usaha yang dilaksanakan oleh manajemen dalam suatu lembaga atau untuk mengevaluasi secara kuantitatif hasil dari transaksi yang telah di laksanakan oleh bagian suatu lembaga pada periode tertentu, pengukuran kinerja dilakukan dengan menetapkan ukuran kinerja setiap bagian pusat pertanggung jawaban tersebut.

\section{Balance Scorecard}

Balance Scorecard digunakan untuk menyeimbangkan usaha para eksekutif ke kinerja keuangan dan non keuangan. Dari hasil tersebut menyimpulkan bahwa untuk mengukur kinerja eksekutif dimasa yang akan datang, diperlukan ukuran yang komprehensif yang mencakup empat perspektif: perspektif pertumbuhan dan pembelajaran, perspektif proses bisnis internal, perspektif pelanggan, dan perspektif keuangan. Menurut Mulyadi (2014:1) Balanced Scorecard merupakan alat manajemen kontemporer yang didesain untuk 
meningkatkan

kemampuan

perusahaan dalam melipatgandakan

kinerja keuangan luar biasa secara berkesinambungan. Menurut AB Susanto (2014:308) Balanced Scorecard adalah sebuah perangkat strategis (strategic tools) untuk mengevaluasi kinerja perusahaan terhadap sasaran-sasaran yang telah ditetapkan sebelumnya. Dari pengertian tersebut dapat disimpulkan bahwa Balance Scorecard adalah suatu alat ukur kinerja suatu perusahaan yang diturunkan dari visi dan strategi perusahaan yang memberikan gambaran dari segi keuangan yang pengukurannya mencakup 4 (empat) perspektif yaitu : (1) pertumbuhan dan perkembangan, (2) proses bisnis internal, (3) pelanggan, serta (4) keuangan.

\section{Perspektif Balance Scorecard}

1. Perspektif Pertumbuhan dan Pembelajaran

$\begin{array}{lr}\text { Tujuan dimasukkannya } \\ \text { kinerja ini adalah untuk } \\ \text { mendorong perusahaan } & \text { menjadi } \\ \text { organisasi belajar } \quad \text { (learning } \\ \text { organization) } \\ \text { mendorongnya } \\ \text { sekaligus } \\ \text { (Mulyadi: 2014). }\end{array}$

perspektif ini dalam tiga prinsip yaitu :

\section{a. People}

Tenaga kerja pada perusahaan dewasa ini lebih lanjut dituntut untuk dapat berfikir kritis dan melakukan evaluasi terhadap proses dan lingkungan untuk mendapatkan usulan perbaikan. Dalam kriterianya dengan sumber daya manusia ada dua hal yang perlu ditinjau dalam menerapkan

Balance Scorecard :

a. Tingkat Perputaran Karyawan (Retensi Karyawan)

Retensi karyawan adalah kemampuan perusahaan untuk mempertahankan pekerja-pekerja terbaiknya untuk terus berada dalam organisasinya.

b. Produktivitas Karyawan Produktivitas merupakan hasil dari pengaruh rata-rata dari peningkatan keahlian dan semangat inovasi, perbaikan proses internal, dan tingkat kepuasan pelanggan.

\section{Perspektif Proses Bisnis Internal}


Dalam perspektif proses bisnis internal, perusahaan harus mengidentifikasi proses internal yang penting dimana perusahaan harus melakukan dengan sebaikbaiknya. Masing-masing perusahaan mempunyai seperangkat proses penciptaan nilai yang unik bagi pelanggannya. Secara umum Kaplan dan Norton membaginya menjadi tiga prinsip dasar yaitu :

a. Inovasi

Pengukuran kinerja dalam proses inovasi selama ini kurang mendapat perhatian dibandingkan pengukuran kinerja yang dilakukan dalam proses operasi.

b. Operasi

Tahap ini merupakan tahap akhir dimana perusahaan secara nyata berupaya untuk memberikan solusi kepada para pelanggannya dalam memenuhi kebutuhan dan keinginan langganan dan kebutuhan mereka.

c. Layanan paska jual

Dalam tahap ini perusahaan berupaya memberikan manfaat tambahan kepada para pelanggan yang telah membeli produk-produknya dalam bentuk layanan pasca transaksi.

\section{Perspektif Pelanggan}

Suatu produk atau jasa dikatakan mempunyai nilai bagi konsumennya jika manfaat yang diterima relatif lebih tinggi daripada pengorbanan yang dikeluarkan oleh pelanggan tersebut untuk mendapat produk atau jasa itu. Dalam perspektif pelanggan terdapat dua kelompok perusahaan, yaitu :

Kelompok-kelompok pengukuran inti pelanggan yaitu :

a) Kemampuan Mempertahankan Pelanggan

(Customer

\section{Retention)}

Tingkat

kemampuan

perusahaan

untuk

mempertahankan hubungan dengan konsumennya yang mungkin seberapa besar perusahaan mempertahankan pelanggan lama.

b) Kemampuan Mendapatkan Konsumen Baru (Customer Aquicition) Tingkat kemampuan perusahaan demi memperoleh dan menarik konsumen baru dalam pasar. 
1) Tingkat Kepuasan Konsumen (Customer Satiffation)

Merupakan suatu tingkat kepuasan konsumen terhadap kriteria kinerja atau nilai tertentu yang diberikan oleh perusahaan.

2) Tingkat Protabilitas Konsumen (Customer Profitability)

Mengukur seberapa besar keuntungan yang berhasil diperoleh perusahaan dari penjualan kepada konsumen atau segmen pasar.

\section{Perspektif Keuangan}

Menurut AB Susanto (2014:309) Ukuran kinerja keuangan menunjukan apakah strategi, sasaran tinggi, inisatif strategi dan implementasinya mampu memberikan kontribusi dalam menghasilkan laba bagi perusahaan. Mengidentifikasi tiga tahapan dari siklus kehidupan bisnis yaitu :

1. Pertumbuhan (Growth)

Growth adalah tahap pertama dan tahap awal dari siklus kehidupan bisnis. Pada tahap ini suatu perusahaan memiliki produk atau jasa yang secara signifikan memiliki tingkat pertumbuhan yang baik sekali atau paling tidak memiliki potensi untuk berkembang biak.

2. Bertahan (Sustain Stage)

Sustain stage suatu tahap dimana perusahaan masih melakukan investasi dengan mempersyaratkan tingkat pengembalian yang terbaik.

3. Menuai (Harvest)

Tahap ini merupakan tahap kematangan (mature), suatu tahap dimana perusahaan melakukan panen terhadap investasi yang dibuat pada dua tahap sebelumnya. Perusahaan tidak lagi melakukan investasi lebih jauh kecuali hanya untuk pemeliharaan peralatan dan perbaikan fasilitas, tidak untuk melakukan ekspansi atau membangun suatu kemampuan baru.

Indikator Pelayanan Penginapan Hotel

Indikator-indikator pelayanan hotel dapat digunakan unuk mengetahui tingkat pemanfaatan, mutu, dan efisiensi pelayanan hotel. Indikator-indikator tersebut bersumber dari sensus harian menginap, yaitu : 
1. $\mathrm{BOR}$ (Bed Occupancy Ratio = Angka Penggunaan Tempat Tidur)

BOR adalah "The rasio of patient service day to inpatient bed count day in a period under consideration".

Rumus $:$ BOR $=$ (Jumlah hari pelayan Hotel /(Jumlah tempat tidur X Jumlah hari dalam satu periode)) X $100 \%$

2. BTO (Bed Turn Over= Angka Perputaran Tempat Tidur)

BTO adalah frekuensi pemakaian tempat tidur pada satu periode, berapa kali tempat tidur dipakai dalam satu satuan waktu tertentu idealnya dalam satu tahun, satu tempat tidur rata-rata dipakai 4050 kali.

Rumus : $\mathrm{BTO}=$ Jumlah pelanggan / jumlah tempat tidur.

\section{Hotel}

Pengertian $\begin{array}{r}\text { Hotel } \\ \text { adalah }\end{array}$
adalah Pengertian hotel perusahaan atau
sebuah bangunan, pan
usaha yang menyediakan jasa inap
dan juga menyediakan makanan
dan minuman bagi tamu yang
datang serta mempunyai fasilitas
jasa lainnya. Yang mana semua

fasilitasnya juga di peruntukkan bagi masyarakat umum.

Permasalahan di Hotel Elresas saat ini yaitu harus tetap meningkatkan kualitas pelayanan, kinerja karyawan serta memaksimalkan laba setiap periode, agar Hotel Elresas dapat berdaya saing dan mampu menciptakan sumber daya manusia yang tangguh dan beriman. Hotel Elresas Lamongan merupakan salah satu Hotel di Lamongan yang berusaha memberikan pelayanan penginapan secara profesionalisme dan meningkatkan mutu terus menerus. Memaksa pihak Hotel Elresas Lamongan untuk selalu memperbaiki kinerjanya, agar dapat menambah kepercayaan pengunjung atas pelayanan Hotel Elresas Lamongan. Kepercayaan ini sangatlah penting, mengingat pengunjung merupakan pengguna jasanya.

\section{METODE PENELITIAN}

\section{Jenis Penelitian}

Agar penelitian ini lebih terarah serta sesuai dengan tujuan yang diinginkan, penulis menggunakan jenis penelitian 
kuantitatif dan kualitatif untuk mengolah data-data yang diperoleh dari lokasi penelitian. Menurut Sugiyono (2012:7) penelitian kuantitatif dapat diartikan sebagai metode penelitian yang berlandaskan pada filsafat positivesme, digunakan untuk meneliti pada populasi atau sampel tertentu. Menurut Sugiyono (2012:7)

Penelitian kualitatif adalah metode penelitian yang berlandaskan pada filsafat postpositivisme, digunakan untuk meneliti pada kondisi obyek alamiah, (sebagai lawannya adalah eksperimen) dimana peneliti adalah sebagai instrument kunci, teknik pengumpulan data dilakukan secara gabungan, analisis data bersifat induktif/kualitatif, dan hasil penelitian kualitatif lebih menekankan makna dari pada generalisasinya.

Penelitian ini juga dapat digolongkan sebagai metode survei, yaitu metode yang digunakan untuk mendapatkan data dari tempat tertentu yang alamiah (bukan buatan), tetapi peneliti melakukan perlakuan dalam pengumpulan data, misalnya dengan mengedarkan kuisioner, test, dan wawancara terstruktur (Sugiyono, 2012:6).

\section{Populasi}

Menurut Sugiyono (2016:80) adalah wilayah generalisasi yang terdiri atas subyek atau obyek yang mempunyai kualitas dan karakteristik tertentu yang ditetapkan oleh peneliti untuk dipelajari dan kemudian ditarik kesimpulannya.Populasi dalam penelitian ini adalah Pimpinan, karyawan, pelanggan dan data yang ada pada Hotel Elresas Lamongan.

\section{Sampel}

Menurut Sugiyono (2012:80)adalah bagian dari jumlah dan karakteristik yang dimiliki oleh populasi. Pengambilan sampel digunakan untuk sekedar penaksiran, sampel dalam penelitian ini adalah Pimpinan, karyawan, pelanggan dan data yang ada pada Hotel Elresas Lamongan yang berjumlah 100 responden.

\section{Metode Analsis Data}

Analisis data adalah proses penyederhanaan data ke dalam bentuk mudah dibaca dan diinterprestasikan. Data ini mencakup tentang pelaksanaan pelayanan, persaingan, strategi dan lain lain (Sugiyono, 2013:60). 
Metode Analisis Data dalam penelitian ini adalah perhitungan Balance Scorecard, Uji Validitas, Uji Realibilitas dan Regresi Linear Berganda.

\section{KEADAAN UMUM DAERAH PENELITIAN}

Hotel Elresas adalah Hotel keluarga yang dikelola secara syariah yang terletak di jantung kota Lamongan, dengan posisi strategis ini menjadikan Hotel Elresas sebagai tujuan peristirahatan yang nyaman dan mudah menjangkau ke berbagai tempat baik tempat hiburan, perkantoran, maupun perbelanjaan. Kehadiran Hotel Elresas sendiri dalam sejarahnya tidak terlepas dari upaya perjuangan bisnis dari salah satu putra Lamongan yakni Bapak Haji Syamsyuri (Almarhum) pada tahun 2014.

\section{HASIL DAN PEMBAHASAN}

Pengukuran Kinerja Hotel Elresas

Lamongan dengan menggunakan

\section{Balance Scorecard}

Pada perspektif pertumbuhan dan pembelajaran pada tahun 2017 setiap karyawan dalam satu tahun mampu mendapatkan rata-rata 81.020.625 dalam satu tahun sedangkan pada tahun selanjutnya yaitu tahun 2018 menurun menjadi 79.220.167, sedangkan pada retensi karyawan menunjukan hasil yang 7,14\% pada tahun 2017 dan 3,33\% tahun 2018, dalam perspektif pertumbuhan dan pembelajaran menunjukan hasil yang kurang baik yaitu belum mampu menaikan hasil pendapatan perusahaan dan perusahaan belum mampu menjaga kesejahteraan karyawannya.

Untuk perspektif proses bisnis internal, pada proses inovasi tahun 2017 tidak mampu menyediakan inovasi sehingga mendapatkan $0 \%$ selanjutnya pada tahun 2018 mampu menambah inovasi bagi perusahaan menjadi 33,33\%, untuk proses operasi dihitung menggunakan BOR (Bed Occupancy Ratio) pada tahun 2017 hasil yang diperoleh 2,36\% , pada tahun 2018 hasil yang diperoleh yaitu 2,38\%. Selanjutnya menggunakan BTO (Bed Turn Over) pada tahun 2017 mampu mendapatkan hasil $31,94 \%$ per tahun dan meningkat menjadi $38,89 \%$ pada tahun 2018.

Pada perspektif berikutnya yaitu perspektif pelanggan, pada tahun 2017 sebesar $26,98 \%$ 
sedangkan pada tahun 2018 tingkat akuisisi pelanggan yaitu $29,41 \%$ dan selanjutnya retensi pelanggan pada tahun 2017 sebesar 73,02\% sedangkan pada tahun 2018 sebesar $73,68 \%$ yang terakhir pada tingkat pelanggan komplain pada tahun 2017 mendapatkan rata-rata $0,381 \%$ per tahun dan turun menjadi $0,21 \%$ pada tahun 2018.

Selanjutnya perspektif keuangan, dalam perspektif keuangan Rasio Rentabilitas pada profit margin pada tahun 2017 mendapatkan profit sebesar $83,32 \%$ sedangkan pada 2018 mengalami kenaikan menjadi 77,63\%, sedangkan pada ROA (Return On Asset) pada tahun 2017 mencapai presentasi $26,41 \%$ dan mengalami peningkatan pada tahun 2018 yaiu 30,46\%. Pada Rasio Likuiditas current ratio pada tahun 2017 mendapat hasil $165,71 \%$ dan pada tahun 2018 mendapat hasil 168\%, quick ratio pada tahun 2017 mendapat hasil $155 \%$ dan pada tahun 2018 mendapat hasil $161,25 \%$, yang terakhir yaitu cash ratio pada tahun 2017 mendapat hasil 145,99\% dan pada tahun 2018 mendapat hasil $151,63 \%$.

\section{Analisa Data}

1. Uji Validitas

Hasil perhitungan uji validitas Prespektif Pembelajaran dan Pertumbuhan $\left(\mathrm{X}_{1}\right)$ dengan item $\mathrm{X}_{1.1}=0,767$ item $\mathrm{X}_{1.2}=0,630$ item $\mathrm{X}_{1.3}=0,427$ lebih besar dari r tabel jadi dapat disimpulkan bahwa semua instrument dalam variabel produk adalah valid, hal ini dibuktikan dengan nilai masing-masing item $r_{\text {hitung }}>r_{\text {tabel. }}$.

Hasil perhitungan uji validitas Prespektif Proses Bisnis Internal $\left(\mathrm{X}_{2}\right)$ dengan item $\mathrm{X}_{2.1}=0,679$ item $\mathrm{X}_{2.2}=0,876$ item $\mathrm{X}_{2.3}=$ 0,795 lebih besar dari $r$ tabel jadi dapat disimpulkan bahwa semua instrument dalam variabel produk adalah valid, hal ini dibuktikan dengan nilai masing-masing item $r_{\text {hitung }}>r_{\text {tabel. }}$.

Hasil perhitungan uji validitas Prespektif Pelanggan $\left(\mathrm{X}_{3}\right)$ yaitu dengan item $X_{3.1}=0,248$ item $X_{3.2}$ $=0,798$ item $X_{3.3}=0,832$ item $\mathrm{X}_{3.4}=0,784$ lebih besar dari $\mathrm{r}$ tabel jadi dapat disimpulkan bahwa semua instrument dalam variabel produk adalah valid, hal ini dibuktikan dengan nilai masing-masing item $r_{\text {hitung }}>r_{\text {tabel. }}$. 
Hasil perhitungan uji validitas Prespektif Keuangan $\left(\mathrm{X}_{4}\right)$ dengan item $\mathrm{X}_{4.1}=0,845$ item $\mathrm{X}_{4.2}=$ 0,783 item $\mathrm{X}_{4.3}=0,865$ lebih besar dari $r$ tabel jadi dapat disimpulkan bahwa semua instrument dalam variabel produk adalah valid, hal ini dibuktikan dengan nilai masing-masing item $r_{\text {hitung }}>r_{\text {tabel }}$

Hasil perhitungan uji validitas Kinerja $(\mathrm{Y})$ dengan item $\mathrm{Y}_{1}=$ 0,528 item $\mathrm{Y}_{2}=0,957$ item $\mathrm{Y}_{3}=$ 0,729 lebih besar dari $\mathrm{r}$ tabel jadi dapat disimpulkan bahwa semua instrument dalam variabel produk adalah valid, hal ini dibuktikan dengan nilai masing-masing item $r_{\text {hitung }}>r_{\text {tabel. }}$.

2. Uji Reliabilitas

Hasil perhitungan uji reliabilitas variabel Perspektif Pembelajaran dan Pertumbuhan 0,680 Perspektif Bisnis Internal 0,816 Perspektif Pelanggan sebesar $\quad 0,756 \quad$ Prespektif Keuangan sebesar 0,838 dan Kinerja sebesar 0,751. Dari masing-masing variabel diperoleh koefisien alpa lebih besar dari 0,60 untuk instrumen yang berupa alat tes atau angket, apabila koefisien alpa diatas 0,60 maka dapat disimpulkan bahwa alat ukur tersebut dikatakan reliabel.

3. Regresi Linier Berganda

Hasil perhitungan regresi berganda menghasilkan persamaan sebagai berikut: $\mathrm{Y}=8,025+0,244 \mathrm{X}_{1}+0,530 \mathrm{X}_{2}+$ $0,258 X_{3}-0,282 X_{4}$, yang diartikan sebagai berikut :

$\mathrm{a}=8,025$ artinya konstanta yang menyatakan bahwa jika variabel bebas yaitu Perspektif Pertumbuhan dan Perkembangan $\quad\left(\mathrm{X}_{1}\right)$, Perspektif Proses Bisnis Internal $\left(\mathrm{X}_{2}\right), \quad$ Perspektif Pelanggan $\quad\left(\mathrm{X}_{3}\right), \quad$ dan Perspektif Keuangan $\left(\mathrm{X}_{4}\right)$ konstan, maka kinerja sebesar 8,025.

$b_{1}=0,244$ artinya koefisien regresi Perpektif Pembelajaran dan Pertumbuhan $\left(\mathrm{X}_{1}\right)$ diperoleh sebesar 0,244 dengan tanda positif. Hal ini apabila Perspektif Pembelajaran dan Pertumbuhan dinaikkan sebesar 1 satuan, maka Kinerja akan meningkat sebesar 0,244 dengan asumsi variabel lain yang 


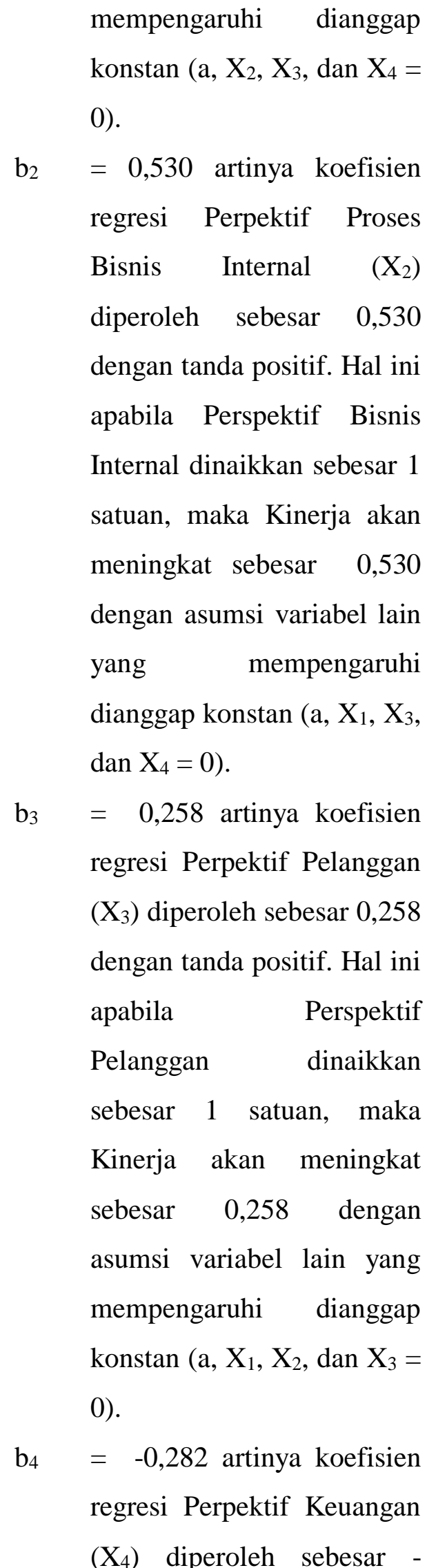

0,282 dengan tanda negative. Hal ini apabila Perspektif Keuangan dinaikkan sebesar 1 satuan, maka Kinerja akan mengalami penurunan sebesar -0,282 dengan asumsi variabel lain yang mempengaruhi dianggap konstan $\left(\mathrm{a}, \mathrm{X}_{1}, \mathrm{X}_{2}\right.$, dan $\mathrm{X}_{3}=$ $0)$.

\section{Uji t}

Perhitungan uji $\mathrm{t}$ dapat dilihat hasilnya nilai thitung Perspektif Pembelajaran dan Pertumbuhan $\left(\mathrm{X}_{1}\right)=2,818>\mathrm{t}_{\text {tabel }} 1,984$, Perspektif Proses Bisnis Internal $\left(\mathrm{X}_{2}\right)=9,588>\mathrm{t}_{\text {tabel }} 1,984$, Perspektif Pelanggan $\left(\mathrm{X}_{3}\right)=$ $4,464>\mathrm{t}_{\text {tabel }} 1,984$, Perspektif Keuangan $\left(\mathrm{X}_{4}\right)=-5,400<\mathrm{t}_{\text {tabel }}-$ 1,984, dan sehingga $\mathrm{H}_{0}$ ditolak dan $\mathrm{H}_{1}$ diterima. Hal ini menunjukkan bahwa Perspektif Pertumbuhan dan Pembelajaran $\left(\mathrm{X}_{1}\right)$, Perspektif Proses Bisnis Internal $\quad\left(\mathrm{X}_{2}\right), \quad$ Perspektif Pelanggan $\left(\mathrm{X}_{3}\right)$, dan Perspektif Keuangan $\left(\mathrm{X}_{4}\right)$ secara parsial mempunyai pengaruh yang 
signifikan terhadap kinerja pada Hotel Elresas Lamongan.

5. Uji F

Uji $F$ pada perhitungan diatas diketahui bahwa $F_{\text {hitung }}$ sebesar $(45,851)>F_{\text {tabel }}(2,700)$ dengan tarif signifikan a $=0,05$, sehingga $\mathrm{H}_{0}$ ditolak dan $\mathrm{H}_{1}$ diterima. Dapat disimpulkan bahwa secara simultan variabel bebas bahwa Perspektif Pertumbuhan dan Pembelajaran $\left(\mathrm{X}_{1}\right)$, Perspektif Proses Bisnis Internal $\left(\mathrm{X}_{2}\right), \quad$ Perspektif Pelanggan $\left(\mathrm{X}_{3}\right)$, dan Perspektif Keuangan $\left(\mathrm{X}_{4}\right)$ berpengaruh secara nyata terhadap Kinerja. Sehingga menyatakan bahwa variabel bahwa Perspektif Pertumbuhan dan Pembelajaran $\left(\mathrm{X}_{1}\right)$, Perspektif Proses Bisnis Internal $\quad\left(\mathrm{X}_{2}\right), \quad$ Perspektif Pelanggan $\left(\mathrm{X}_{3}\right)$, dan Perspektif Keuangan $\left(\mathrm{X}_{4}\right)$ secara bersamasama berpengaruh signifikan terhadap kinerja pada Hotel Elresas Lamongan.

\section{SIMPULAN}

Berdasarkan hasil penelitian yang telah dilakukan maka dapat ditarik beberapa kesimpulan diantaranya sebagai berikut:

Berdasarkan perhitungan Balance Scorecard dan analisis data Perspektif Pertumbuhan dan Pembelajaran, Perspektif Proses Bisnis Internal, Perspektif Pelanggan dan Perspektif Keuangan pada Kinerja di Hotel Elresas Lamongan. Penerapan metode Balance Scorecard dapat digunakan untuk mengetahui bagaimana kinerja suatu perusahaan. Dengan hasil penelitian yang didukung jurnal dari Sutri Handayani (2012) yang menyatakan bahwa penerapan perhitungan dengan menerapkan Balance Scorecard pada PDAM Kabupaten Lamongan dapat untuk mengukur kinerja perusahaan.

Berdasarkan perhitungan Balance Scorecard jumlah skor pada Hotel Elresas Lamongan yaitu 7 skor. Dengan hasil penelitian yang didukung jurnal dari Ade Afrizal (2013) pada Hotel Panorama Tanjungpinang mendapatkan total skor yaitu 6. Maka kinerja Hotel Panorama Tanjungpinang dan Hotel Elresas Lamongan dapat dikatakan baik. 
Berdasarkan perhitungan analisis data Perspektif Proses Bisnis Internal lebih dominan sebagai tolak ukur pengukuran kinerja pada Hotel Elresas Lamongan. Karena nilai thitung lebih besar dari perspektif lainnya dengan hasil t hitung 9,588 > t tabel 1,984.

\section{DAFTAR PUSTAKA}

AB Susanto. 2014. Manajemen Strategik Komprehensif. Jakarta: Erlangga.

Ade Afrizal. 2013. Analisis Kinerja

Perusahaan dengan Pendekatan Balanced Scorecard (Studi Kasus pada Hotel Panorama Tanjungpinang). Skripsi. Tanjungpinang.

Aurora, Novella. 2010. Penerapan Balanced Scorecard Sebagai Tolok

Ukur Pengukuran Kinerja:

Studi Kasus Pada RSUD Tugurejo

Semarang. Skripsi. Semarang

: Universitas Diponegoro.

Arsenia, Laksmita Venda. 2011. Analisis Pengukuran Kinerja Perusahaan Dengan Metode
Balanced Scorecard (Studi Kasus Pada PT Bank Jateng Cabang Utama Semarang). Skripsi. Semarang Perpustakaan FEB Universitas Diponegoro.

Astono, Arif Tri. 2013. Pengukuran Kinerja PT Asuransi Jasindo Semarang dengan Pendekatan Balanced Scorecard (Studi kasus pada Karyawan PT Asuransi Jasindo Semarang). Skripsi.Semarang

Perpustakaan FISIP Universitas Diponegoro.

Awan Febrianto. 2016. Analisis Pengukuran Kinerja Perusahaan dengan Metode Pendekatan Balanced Scorecard (Studi Kasus Pada Koperasi Simpan Pinjam (KSP) Lohjinawe Rembang). Skripsi :Universitas Diponegoro.

Didyk. 2010. Analisis Kinerja Hotel Pita Maha A Tjampuhan Resort \& Spa dengan Menggunakan Metode Balanced Scorecard. Skripsi. Bali : Universitas Udayana. 
Hikmat, Mahi.

2011. Praktis

Penulisan Naskah Iklan.

Jakarta : PT. Gramedia Pustaka

Utama.

Kumalasari, Y.S. 2010. Evaluasi

Terhadap Kinerja Unit

Usaha Syariah pada Bank

Konvensional dengan

Perspektif

Balance

Scorecard.

Skripsi

Universitas Diponegoro.

Lailiyah, S. 2012. Pengukuran

Kinerja Rumah Sakit dengan Balanced

Scorecard (Studi Kasus pada

Rumah Sakit Umum Daerah

Ngudi Waluyo

Wlingi). Skripsi. Yogyakarta.

Makhijani, Naresh dan Creelman, James. 2012. Menciptakan

Balanced Scorecard untuk

Organisasi Jasa Keuangan.

Jakarta: Erlangga.

Mashuri Achmad, 2013. Penerapan

Balance Scorecard Sebagai

Tolak Ukur Pengukuran

Kinerja (Studi Kasus Pada

Rumah Sakit Umum Daerah

Dr. Soegiri Lamongan)
Moeheriono. 2012. Pengukuran Kinerja Berbasis

Kompetensi. Jakarta : Raja Grafindo Persada.

Moleong, Lexy J. 2012. Metodologi Penelitian Kualitatif. Bandung : PT Remaja. Rosdakarya.

Mulyadi. 2014. Sistem Terpadu Pengelolaan Kinerja Personal Berbasis Balanced Scorecard. Yogyakarta: Sekolah Tinggi Ilmu Manajemen YKPN.

Mulyadi. 2014. Balance Scorecard Sebagai Inti Sistem Manajemen Strategik. Jakarta : Prima Nusantara Manajemen.

Mulyadi, 2015, Akuntansi Manajemen : Konsep, Manfaat dan Rekayasa, edisi 3, Jakarta, Salemba Empat

Novanditya, Indra. 2013. Pengukuran Kinerja Perusahaan dengan Menggunakan Pendekatan Balanced Scorecard (Studi Kasus pada Perusahaan 
Vulkanisir Ban CV Roda Mas

Jaya,Semarang). Skripsi.

Semarang : Perpustakaan

FISIP Universitas Diponegoro.

Prakosa, Yuniarsa A. 2013.

"PengukuranKinerja

Perusahaan dengan

Pendekatan

Balance

Scorecard (Studi Kasus Pada PT Waskita Karya)". Skripsi

Fakultas Ekonomi Universitas

Diponegoro.

Robert s. Kaplan. 2013. The

Balance Scorecard. Jakarta

:Erlangga.

Sapardianto. 2013. Analisis

Pengukuran Kinerja

Perusahaan dengan Konsep

Balanced Scorecard (Studi

Kasus pada PT Trustco

Insan Mandiri Samarinda).

e-J Administrasi Bisnis.

Sarjono, H. 2010. Penerapan

Metode Balanced Scorecard

Sebagai

Suatu

Sistem Pengukuran Kinerja pada PT. Dritama

Brokerindo, Jakarta Timur. Jakarta.
Sugiyono. 2012. Metode

PenelitianKuantitatif, kualitatif dan $R \quad \& \quad D$. Bandung : Alfabeta.

2013. Metode Penelitian Kombinasi (Mixed Methode). Bandung : Alfabetha

Suhardiman, Ivan 2012. Penerapan Balanced Scorecard Sebagai Tolak Ukur Kinerja Instansi Pemerintah (Studi Kasus pada bidang Kesejahteraan Sosial, Dinas Sosial dan Tenaga Kerja Kota Tanjungpinang). Skripsi Tanjungpinang : Universitas Maritim Raja Ali Haji.

Sutri Handayani. 2012. Analisis Penilaian Kinerja dengan Pendekatan Balanced Scorecard (Studi Kasus pada PDAM Kabupaten Lamongan). Skripsi. Lamongan.

Syamsiyah. 2013. Analisis Pengukuran Kinerja

Organisasi dengan Metode Balanced Scorecard (Studi Kasus pada KSU Karyawan 
Pemerintah Kota Semarang).

Skripsi. Semarang :

Perpustakaan FISIP

Universitas Diponegoro.

Wahyuni, Sri. 2011. Analisis

Balance Scorecard Sebagai

Alat Pengukuran Kinerja

Pada PT. Semen Bosowa

Maros. Skripsi. Makasar :

Universitas Hasanudin.

Zudia, M. 2010. Analisis Penilaian

Kinerja Organisasi dengan

Menggunakan Konsep

Balance Scorecard Pada PT

Bank Jateng Semarang.

Skripsi: Universitas

Diponegoro. 